\title{
Correction to: Occurrence of the giant liver fluke, Fascioloides magna, in sympatric wild ungulates in one area in the Upper Palatinate Forest (northeastern Bavaria, Germany)
}

\author{
S. Rehbein ${ }^{1} \cdot$ M. Visser $^{1} \cdot$ D. Hamel ${ }^{1} \cdot$ H. ReindI ${ }^{2}$ \\ Published online: 22 February 2021 \\ (C) Springer-Verlag GmbH Germany, part of Springer Nature 2021
}

Correction to: Parasitol Res (2021) 120:553-561

https://doi.org/10.1007/s00436-020-06996-7

The original version of the above article contains some errors. In two sentences in the INTRODUCTION the words "estates" or "estate" were replaced during the text handling by "states" and "state", respectively.

The correction on the sentences are listed below.

(1) INTRODUCTION, second paragraph, fourth sentence: "However, both white-tailed deer and wapiti have been imported into and were translocated between estates in Moravia and Bohemia ...”.

(2) INTRODUCTION, third paragraph, third sentence: "These findings indicate a dispersal of the parasite from the location of the first records in the forests of the Görlitzer Heide (Puszcza Zgorzelecka), where wapiti had been introduced in the neighboring estate Klitschdorf ..."

Publisher's note Springer Nature remains neutral with regard to jurisdictional claims in published maps and institutional affiliations.

The online version of the original article can be found at https://doi.org/ 10.1007/s00436-020-06996-7

S. Rehbein

steffen.rehbein@boehringer-ingelheim.com

1 Boehringer Ingelheim Vetmedica GmbH, Kathrinenhof Research

Center, Walchenseestr 8-12, 83101 Rohrdorf, Germany

2 Tierärztliche Fachpraxis für Kleintiere, Schießtrath 12,

92709 Moosbach, Germany 